\title{
Adenosine 5'-monophosphate ameliorates D-galactosamine/lipopolysaccharide-induced liver injury through an adenosine receptor-independent mechanism in mice
}

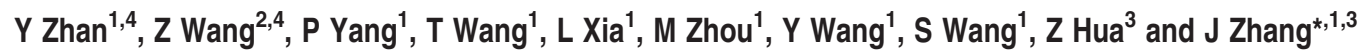

D-galactosamine (GaIN)/lipopolysaccharide (LPS)-induced lethality and acute liver failure is dependent on endogenously produced inflammatory cytokines. Adenosine has been proven to be a central role in the regulation of inflammatory response. It is not entirely clear that which adenosine action is actually crucial to limiting inflammatory tissue destruction. Here we showed that GaIN/LPS challenge elevated hepatic adenosine and induced lethality in adenosine receptor-deficient mice with equal efficiency as wild-type mice. In GaIN/LPS-treated mice, pretreatment with adenosine $5^{\prime}$-monophosphate $\left(5^{\prime}\right.$-AMP) significantly elevated hepatic adenosine level and reduced mortality through decreasing cytokine and chemokine production. In RAW264.7 cells, 5'-AMP treatment inhibited the production of inflammatory cytokines, which is not mediated through adenosine receptors. $5^{\prime}$-AMP failed to attenuate LPS-induced nuclear factor- $\kappa$ B (NF- $\kappa$ B) p65 nuclear translocation, but reduced LPS-induced recruitment of NF- $\kappa$ B p65 to inflammatory gene promoters and decreased LPS-induced enrichment of H3K4 dimethylation at the tumor necrosis factor- $\alpha$ (TNF- $\alpha$ ) promoter, which was involved in 5'-AMP-induced elevation of cellular adenosine and a decline of methylation potential. In vitro biochemical analysis revealed that adenosine directly attenuated recruitment of NF- $\kappa \mathrm{B}$ to the TNF- $\alpha$ and interleukin- 6 promoters. Our findings demonstrate that $5^{\prime}$-AMP-inhibiting inflammatory response is not mediated by adenosine receptors and it may represent a potential protective agent for amelioration of LPS-induced liver injury.

Cell Death and Disease (2014) 5, e985; doi:10.1038/cddis.2013.516; published online 9 January 2014

Subject Category: Immunity

Acute liver failure (ALF) is one of the most devastating syndromes observed in clinical practice. It is associated with high overall mortality, ranging from 30 to $80 \%$, depending on the underlying etiology. ${ }^{1}$ The commonest causes are acute viral hepatitis, drug overdose, idiosyncratic drug reactions, and ingestion of other toxin. ${ }^{2}$ Liver transplantation is the only therapy that has been proven beneficial, but the rapidity of progression and the variable course of ALF limit its application. ${ }^{3}$ Therefore, there is an urgent need for effective therapy for ALF. An established model for studying ALF in mice is by the co-administration of the hepatocyte-specific transcriptional inhibitor D-galactosamine (GaIN) and the bacterial endotoxin lipopolysaccharide (LPS). ${ }^{4,5}$

In GalN/LPS-induced ALF model, LPS binds with a receptor complex consisting of Toll-like receptor 4 (TLR4), cluster of differentiation 14 (CD14), and MD2. Recruitment of the adaptor protein myeloid differentiation factor-88 (MyD88) initiates a MyD88-dependent pathway that culminates in the early activation of nuclear factor $-\kappa \mathrm{B}(\mathrm{NF}-\kappa \mathrm{B}){ }^{6,7}$ The NF- $\kappa \mathrm{B}$ family is a family of key transcription factors of lymphocytes and macrophages that have a major role in a variety of biological processes, most notably immune responses and inflammation..$^{8,9}$ On stimulation by LPS, activation of NF- $\kappa$ B in macrophages occurs, which leads to the secretion of inflammatory cytokines, including interleukin (IL)-1, IL-6, IL-12, $\mathrm{IL}-1 \beta$ and tumor necrosis factor- $\alpha(\mathrm{TNF}-\alpha) .{ }^{10,11}$ It has been reported that $\mathrm{H} 3 \mathrm{~K} 4$ methylation can regulate the expression of a subset of key NF- $\kappa \mathrm{B}$ downstream inflammatory genes by interacting with $\mathrm{NF}-\kappa \mathrm{B}$ and modulating chromatin remodeling events at their promoters. ${ }^{12}$ TNF- $\alpha$ is the predominant mediator that induces hepatocyte apoptosis and liver injury. ${ }^{13,14}$ Therefore, interfering with proinflammatory cytokines, especially TNF- $\alpha$ expression, is likely to be effective in acute liver injury model. ${ }^{4,10}$

Adenosine $5^{\prime}$-monophosphate (5'-AMP) is a natural molecule of adenosine triphosphate metabolism. Administration of

\footnotetext{
${ }^{1}$ Center for Molecular Metabolism, Nanjing University of Science and Technology, Nanjing 210094, China; ${ }^{2}$ East Hospital, Tongji University, Shanghai 200120, China and ${ }^{3}$ The State Kay Laboratory of Pharmaceutical Biotechnology, Nanjing University, Nanjing, China

*Corresponding author: J Zhang, Center for Molecular Metabolism, Nanjing University of Science and Technology, 200 Xiaolingwei, Najing 210094, China. Tel: +86 258431 8533; Fax: +86 258431 8533; E-mail: jfzhang@mail.njust.edu.cn

${ }^{4}$ These authors contributed equally to this work.

Keywords: LPS; 5'-AMP; TNF- $\alpha$; NF- $\kappa$ B

Abbreviations: ALF, acute liver failure; GalN, o-galactosamine; LPS, lipopolysaccharide; TLR4, Toll-like receptor 4; CD14, cluster of differentiation 14; MyD88, myeloid differentiation factor-88; NF- $\kappa$ B, nuclear factor- $\kappa$ B; IL, interleukin; TNF- $\alpha$, tumor necrosis factor- $\alpha$; $5^{\prime}-\mathrm{AMP}$, adenosine $5^{\prime}$-monophosphate; i.p., intraperitoneal; AST, aspartate transaminase; ALT, alanine transaminase; ELISA, enzyme-linked immunosorbent assay; H\&E, hematoxylin and eosin; PBS, phosphate-buffered saline; ChIP, chromatin immunoprecipitation; AdoMet, S-adenosylmethionine; AdoHcy, S-adenosylhomocysteine; MCP-1, monocyte chemotactic protein-1

Received 10.9.13; revised 16.11.13; accepted 21.11.13; Edited by GM Fimia
} 
exogenous 5'-AMP displays multiple regulatory functions and important physiological roles. ${ }^{15,16}$ Immunomodulatory activity of $5^{\prime}$-AMP as a component of saliva has been identified. ${ }^{17}$ $5^{\prime}$-AMP is also used as a marker of inflammation because it releases histamine and other mediators from immunologically primed mast cells. ${ }^{18}$ It is known that administration of $5^{\prime}$-AMP significantly elevated intracellular adenosine level. ${ }^{19}$ Adenosine is a potent regulator of the inflammatory response. ${ }^{20}$ Adenosine acting as an anti-inflammatory molecule has been complicated by the fact that four different adenosine receptor subtypes exist and have different effects. ${ }^{21-23}$ It is not entirely clear which adenosine action is actually crucial to limiting inflammatory response. In the present study, we identified that the regulation of adenosine receptors is not indispensible for GalN/LPS-induced lethality and the elevated cellular adenosine induced by $5^{\prime}$-AMP pretreatment could directly interfere with NF- $\kappa$ B signaling pathway, suggesting a potential protective agent for amelioration of LPS-induced liver failure.

\section{Results}

GaIN/LPS challenge elevates hepatic adenosine and induces similar lethality in wild-type and adenosine receptor-deficient mice. To investigate how adenosineadenosine receptors signal involves in the development of GalN/LPS-induced ALF, hepatic adenosine was measured at $30 \mathrm{~min}$ after GalN/LPS challenge. Mice injected with GalN/ LPS exhibited about a twofold increase in hepatic adenosine concentrations (Figure 1a), implying a possibility that elevated hepatic adenosine is a feedback prevention of GalN/LPS-induced ALF in early stage. Next, we investigated whether adenosine receptors have a crucial role in preventing function of adenosine. Mice deficient in $A_{1} A R, A_{2 a} A R$, $A_{2 b} A R, A_{3} A R$ and wild-type (WT) mice were challenged with the same dose of GaIN/LPS and the lethality of mice were determined during $24 \mathrm{~h}$. Unexpectedly, administration of GalN/LPS had similar lethality rate in both WT mice and adenosine receptor-deficient mice $\left(A_{1} A R^{-1-}, A_{2 a} A R^{-1-}\right.$, $A_{2 b} A R^{-1-}$ and $A_{3} A R^{-1-}$ mice; Figure $\left.1 b\right)$. These results indicated that loss of adenosine receptor function had no effects on GalN/LPS-induced ALF.

\footnotetext{
Attenuation of ALF in 5'-AMP-pretreated mice. Our previous observations demonstrate that C57BL/6J mice treated with $5^{\prime}$-AMP rather than adenosine markedly increases hepatic adenosine level. To clarify that whether elevating hepatic adenosine before GalN/LPS challenge could prevent from GalN/LPS-induced hepatic injury, mice were treated with 5'-AMP or phosphate-buffered saline (PBS) and injected with GalN/LPS $30 \mathrm{~min}$ later. Expectedly, hepatic adenosine level was markedly elevated at $30 \mathrm{~min}$ after $5^{\prime}$ AMP treatment (Figure 2a). Survival rate in PBS-treated mice $(n=15)$ was $60 \%(8 \mathrm{~h})$ and $33.3 \%(24 \mathrm{~h})$, whereas survival rate in $5^{\prime}$-AMP-treated mice $(n=15)$ was $100 \%(8 \mathrm{~h})$ and $93.3 \%(24 \mathrm{~h})$. The survival rate was not changed after $24 \mathrm{~h}$. There was a significant difference in survival rate between PBS-treated mice and $5^{\prime}$-AMP-treated mice $(P=0.0007$ by log-rank test, Figure $2 \mathrm{~b}$ ). Serum aspartate transaminase (AST) and alanine transaminase (ALT) levels were increased $4 \mathrm{~h}$ after GalN/LPS injection, and they were significantly
}

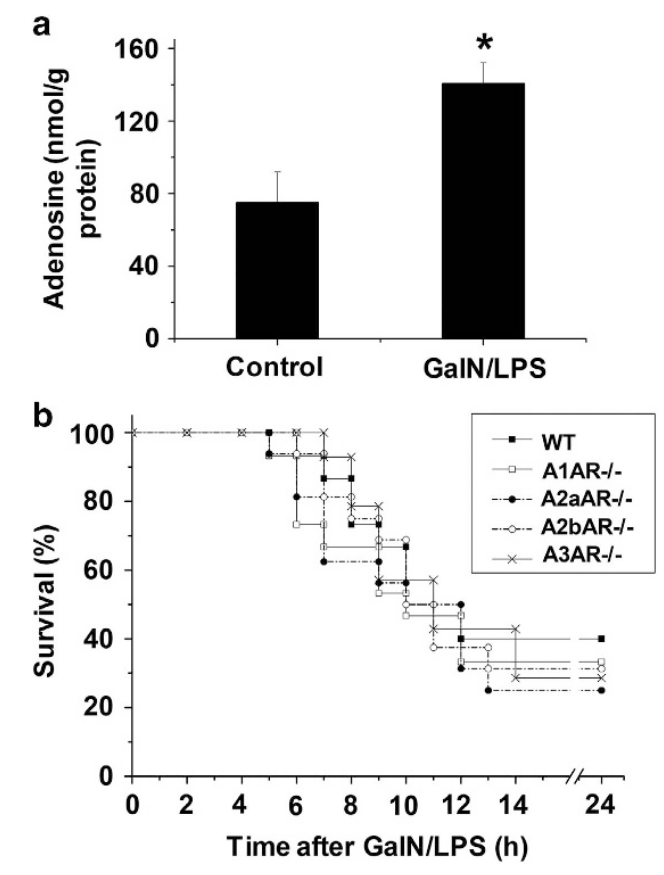

Figure 1 GaIN/LPS challenge elevated hepatic adenosine and induced similar lethality in WT and adenosine receptor-deficient mice. Mice were challenged with GalN (500 mg/kg i.p.)/LPS (5 $\mu \mathrm{g} / \mathrm{kg}$ i.p.). (a) Adenosine levels in liver extracts at $30 \mathrm{~min}$ after challenge with GalN/LPS were quantified by HPLC $(n=5)$. (b) For analysis of survival rate, mortality was assessed every hour for $24 \mathrm{~h}$ (WT, $n=15$; $\left.\mathrm{A}_{1} \mathrm{AR}^{-1-}, n=15 ; \mathrm{A}_{2 \mathrm{a}} \mathrm{AR}^{-1-}, n=16 ; \mathrm{A}_{2 \mathrm{~b}} \mathrm{AR}^{-1-}, n=16 ; \mathrm{A}_{3} \mathrm{AR}^{-I-}, n=14\right)$. Data are expressed as mean \pm S.E. ${ }^{*} P<0.05$ versus control group

lowered in the $5^{\prime}$-AMP/GaIN-LPS group than in the vehicle/ GalN-LPS group (Figures $2 c$ and d). Histologic analysis by hematoxylin and eosin (H\&E) staining showed hepatocyte necrosis and severe inflammatory cell infiltration in the livers of the vehicle/GaIN-LPS group, whereas the area and extent of necrosis was attenuated and the infiltration of inflammatory cells was reduced in the 5'-AMP/GaIN-LPS group (Figure 2e). Moreover, in adenosine receptors knockout mice, 5'-AMP treatment also increased survival rate in GalN/LPS-induced ALF, displaying similar preventing function to WT mice (Supplementary Figure 1).

5'-AMP inhibits proinflammatory cytokines production in the liver. As LPS-induced liver injury is largely mediated by proinflammatory cytokines, ${ }^{11}$ we determined whether $5^{\prime}$-AMP have any effect on proinflammatory cytokine production in the liver. First, we analyzed mRNA levels of proinflammatory cytokines. 5'-AMP treatment significantly decreased the mRNA expression of cytokines, including TNF- $\alpha$, IL- 6 and IL- $1 \beta$, and chemokine such as monocyte chemotactic protein-1 (MCP-1; Figures 3a-d) compared with the vehicle/GalN-LPS group. Second, we measured serum cytokine levels and observed that TNF- $\alpha$ and IL- 6 levels were markedly reduced in the $5^{\prime}$-AMP/GalN-LPS group than in the vehicle/GalN-LPS group (Figures $3 e$ and f).

$5^{\prime}$-AMP decreases the number of macrophage and has no influence on the expressions of CD14, TLR4, and MyD88. Hepatic injury is associated with the expression of 

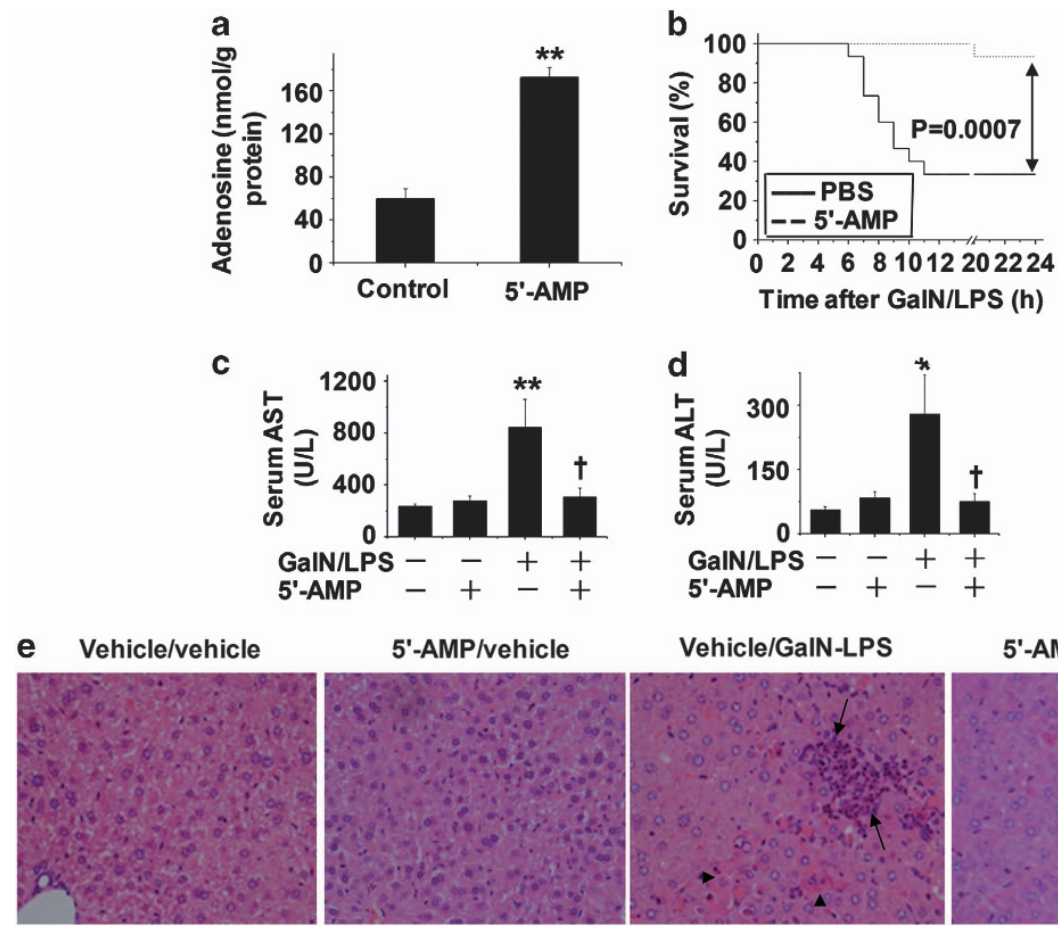

5'-AMP/vehicle

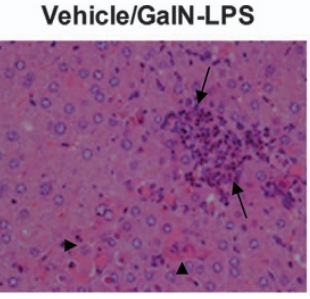

5'-AMP/GaIN-LPS
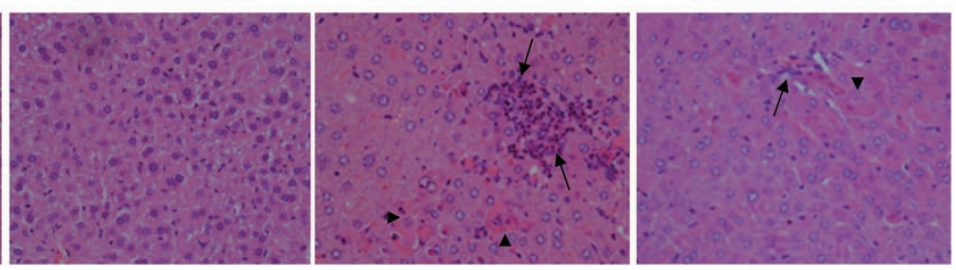

Figure 2 Pretreatment of $5^{\prime}$-AMP attenuates GalN/LPS-induced ALF. Mice were challenged with GaIN ( $500 \mathrm{mg} / \mathrm{kg}$ i.p.) $/ \mathrm{LPS}\left(5 \mu \mathrm{g} / \mathrm{kg}\right.$ i.p.). $5^{\prime}$-AMP (5 mg/20 g i.p.) or PBS was administered at $30 \mathrm{~min}$ before GaIN/LPS injection. (a) For analysis of survival rate, mortality was assessed every hour for $24 \mathrm{~h}(n=15)$. Serum activities of AST (b) and $\operatorname{ALT}(\mathbf{c})$ at $4 \mathrm{~h}$ after induction of ALF were measured $(n=5)$. Data are expressed as mean $\pm S$.E. ${ }^{*} P<0.05,{ }^{* *} P<0.01$ versus vehicle/vehicle group; ${ }^{\dagger} P<0.05$ versus vehicle/ GalN-LPS group. (d) Representative H\&E-stained liver sections of mice at $4 \mathrm{~h}$ after GalN/LPS injection, with arrowheads indicating hepatocyte necrosis and arrows indicating inflammatory cell infiltration. Original magnification: $\times 400$
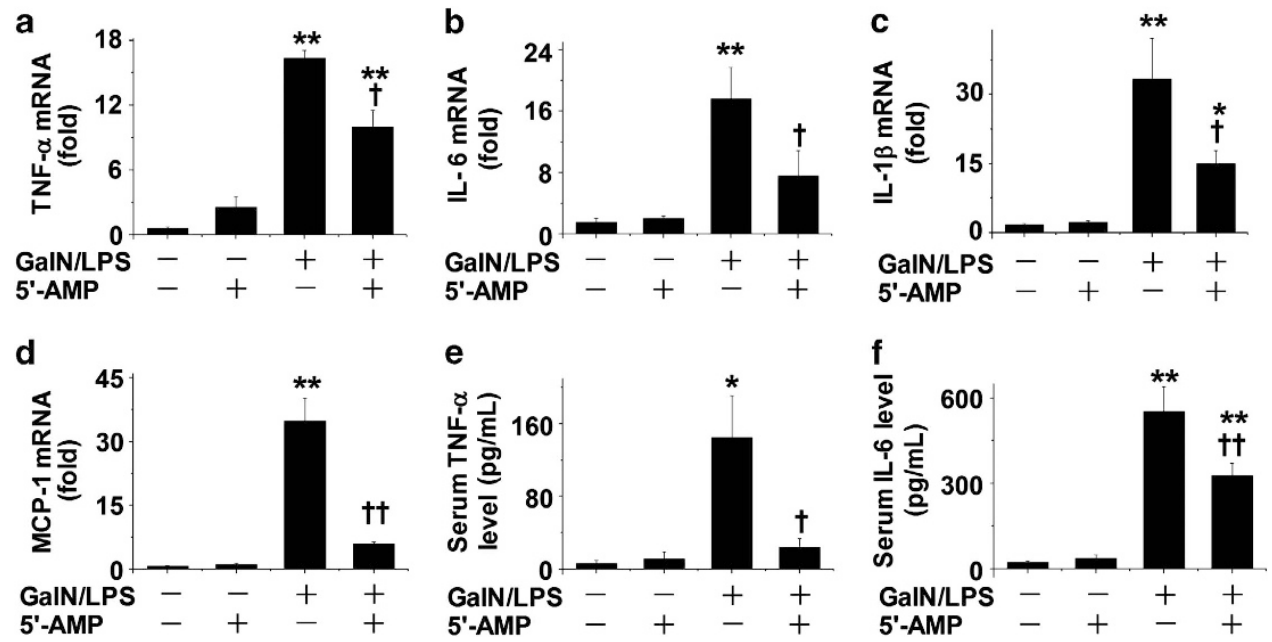

Figure $3 \quad 5^{\prime}$-AMP inhibits proinflammatory cytokine production. Blood and liver samples were collected at $4 \mathrm{~h}$ after GalN/LPS injection with or without $5^{\prime}$-AMP. The hepatic mRNA expressions of TNF- $\alpha$ (a), IL-6 (b), IL-1 $\beta$ (c), and MCP-1 (d) were measured by quantitative RT-PCR $(n=5)$. Serum TNF- $\alpha$ (e) and IL- 6 (f) levels were determined by ELISA kits $(n=5)$. Data are expressed as mean \pm S.E. ${ }^{\star} P<0.05,{ }^{*} P<0.01$ versus vehicle/vehicle group; ${ }^{\dagger} P<0.05,{ }^{\dagger \dagger} P<0.01$ versus vehicle/GalN-LPS group

various proinflammatory cytokines derived from liver cells such as macrophages. ${ }^{24}$ The number of infiltrating monocytes/macrophages was increased in vehicle/GalN-LPS group, whereas this effect was attenuated by $5^{\prime}$-AMP pretreatment (Supplementary Figure 2A). To explore how $5^{\prime}$-AMP attenuates cytokines, we investigated whether 5'-AMP could inhibit TLR signaling pathways. CD14 and
TLR4, as critical components of LPS receptor complex, were determined by RT-PCR analysis. Expressions of CD14 and TLR4 mRNA in the liver were significantly elevated in the vehicle/GalN-LPS group compared with the vehicle/vehicle group. However, pretreatment with $5^{\prime}$-AMP had no influence on the overexpression of CD14 and TLR4 mRNA induced by GalN/LPS (Supplementary Figures 2B and C). MyD88 is an 
important adaptor molecular in TLR signaling pathways; ${ }^{6}$ therefore, MyD88 mRNA expression was examined by RT-PCR analysis and the results showed that there was no difference between each group (Supplementary Figure 2D). Consistent with gene expression result, the protein expression of CD14 and TLR4 was not attenuated by $5^{\prime}$-AMP in the $5^{\prime}$-AMP/GalN-LPS group (Supplementary Figure 2E). Expression of CD14, TLR4, and MyD88 mRNA in RAW264.7 cells were also determined. 5'-AMP had no influence on the expression of CD14, TLR4, and MyD88 in vitro either (data not shown).

5'-AMP suppresses cytokines production in LPSstimulated RAW264.7 cells. To exclude the possibility that reductions of the levels of inflammatory cytokines from the cells were due to direct toxicity of $5^{\prime}$-AMP to the cells, we evaluated cell toxicity of $5^{\prime}$-AMP at different concentrations $(0-1600 \mu \mathrm{M})$ using the MTT assay. 5'-AMP-induced cell toxicity was negligible at concentrations of $25-400 \mu \mathrm{M}$ in RAW264.7 cells (data not shown). TNF- $\alpha$ and IL- 6 were used as an indicator of macrophage response to LPS. ${ }^{25} 5^{\prime}$-AMP significantly attenuated the mRNA expression of TNF- $\alpha$ and IL-6 in RAW264.7 cells. The dose-dependence of TNF- $\alpha$ and IL-6 mRNA showed that at concentration of $400 \mu \mathrm{M}, 5^{\prime}$-AMP exhibited the maximum inhibition (Figures $4 a$ and $b$ ). In addition, compared with control group, LPS induced substantial TNF- $\alpha$ and IL- 6 production in RAW264.7 cells, and 5 '-AMP markedly suppressed TNF- $\alpha$ and IL- 6 production (Figures 4c and d).

5'-AMP attenuates LPS-induced NF- $\kappa$ B activation in RAW264.7 cells. We further investigated the mechanism by which $5^{\prime}$-AMP inhibited the secretion of inflammatory cytokines such as TNF- $\alpha$. NF- $\kappa$ B is a major activator for TNF- $\alpha$ transcription in macrophage. ${ }^{8}$ The nuclear translocation of $\mathrm{NF}-\kappa \mathrm{B}$ p65 was examined in the nuclear extracts of RAW264.7 cells. The results showed that $5^{\prime}$-AMP failed to attenuate LPS-induced nuclear translocation of NF- $\kappa \mathrm{B}$ p65 (Figure $5 \mathrm{a}$ ). As $\mathrm{NF}-\kappa \mathrm{B}$ is the common regulator of TNF- $\alpha$, IL-6, IL-1 $\beta$, and MCP-1 transcription, ${ }^{26-28}$ we analyzed the effect of $5^{\prime}$-AMP on recruitment of NF- $\kappa$ B p 65 to TNF- $\alpha$, IL-6, $\mathrm{IL}-1 \beta$, and MCP-1 gene promoters. As showed in Figure 5, LPS markedly enhanced NF- $\kappa \mathrm{B}$ p65 recruitment to TNF- $\alpha$, IL-6, IL-1 $\beta$, and MCP-1 gene promoters compared with unstimulated cells. However, exposure of cells to $5^{\prime}$-AMP significantly reduced recruitment of $\mathrm{NF}-\kappa \mathrm{B}$ p65 to TNF- $\alpha$, IL-6, and IL-1 $\beta$ gene promoters (Figures $5 b-d$ ). Treatment with $5^{\prime}$-AMP resulted in a slightly decreased tendency of recruitment of NF- $\kappa \mathrm{B}$ p65 to MCP-1 promoter (Figure 5e).

5'-AMP decreases LPS-induced enrichment of H3K4 dimethylation at the TNF- $\alpha$ promoter. In RAW264.7 cells, we observed that the performance of $5^{\prime}$-AMP was similar to that in mice. $5^{\prime}$-AMP treatment raised the intracellular levels of adenosine (but not $5^{\prime}$-AMP) either with or without LPS stimulation (Figure 6a). To investigate whether the effect of $5^{\prime}$-AMP on inflammatory cytokines is mediated through adenosine receptors in vitro, we used a nonspecific adenosine receptor antagonist CGS15943 to block all the adenosine receptor signaling in RAW264.7 cells. 5'-AMP significantly attenuated TNF- $\alpha$ mRNA expression either with or without CGS15943 blocking (Figure 6b), indicating the effects of 5 -AMP was independent on adenosine receptor pathways in vitro. Next, we compared the ratio of S-adenosylmethionine (AdoMet) to S-adenosylhomocysteine (AdoHcy), which presents the intracellular potential of methylation. ${ }^{29}$ This analysis
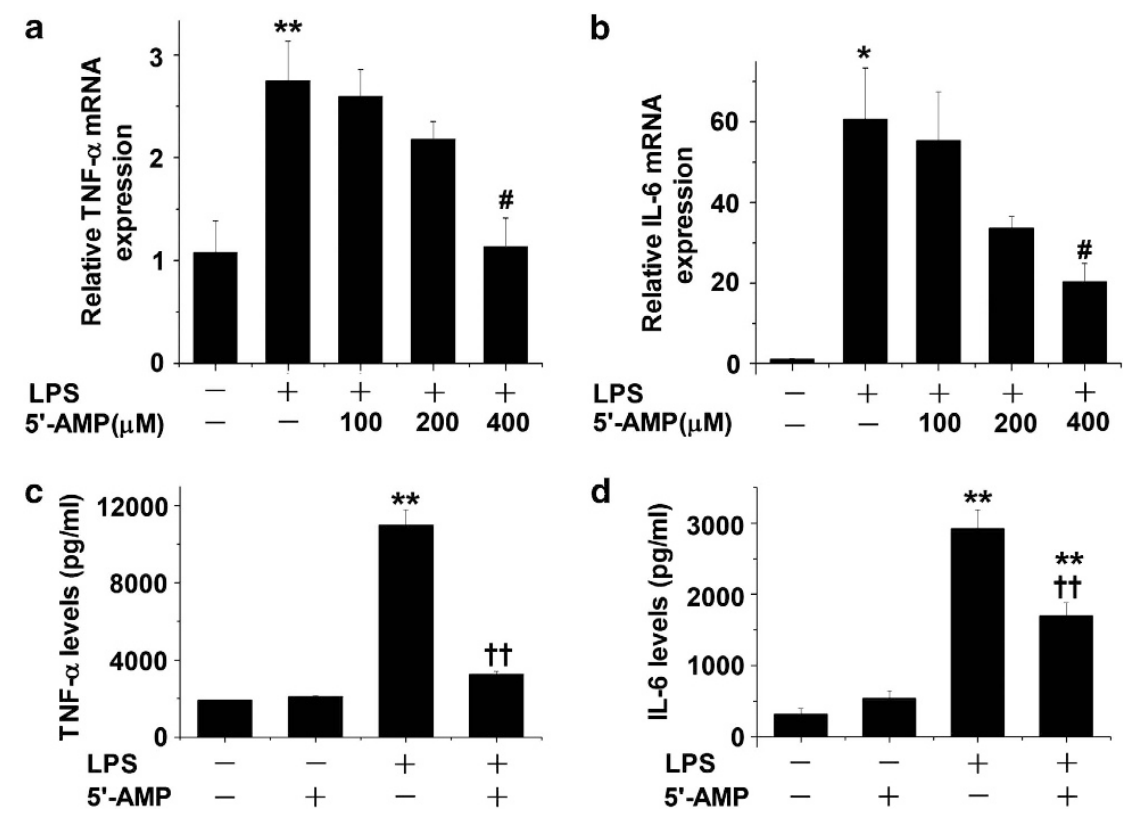

Figure $4 \quad 5^{\prime}$-AMP suppresses cytokine production in LPS-stimulated RAW264.7 cells. RAW264.7 cells were treated with LPS ( $\left.1 \mu \mathrm{g} / \mathrm{ml}\right)$ alone or in the presence of $5^{\prime}$-AMP $(400 \mu \mathrm{M})$ for indicated time. Cells were treated with $5^{\prime}$-AMP 30 min before LPS stimulation. The mRNA expressions of TNF- $\alpha$ (a) and IL-6 (b) were measured by quantitative RT-PCR at $6 \mathrm{~h}$ after LPS stimulation. TNF- $\alpha$ (c) and IL- 6 (d) production in the supernatant were measured by ELISA kits at $24 \mathrm{~h}$ after LPS stimulation. Data are expressed as mean \pm S.E. of four independent experiments. ${ }^{*} P<0.05,{ }^{\star \star} P<0.01$ versus vehicle/vehicle group; ${ }^{\dagger} P<0.05,{ }^{\dagger \dagger} P<0.01$ versus vehicle/LPS group 

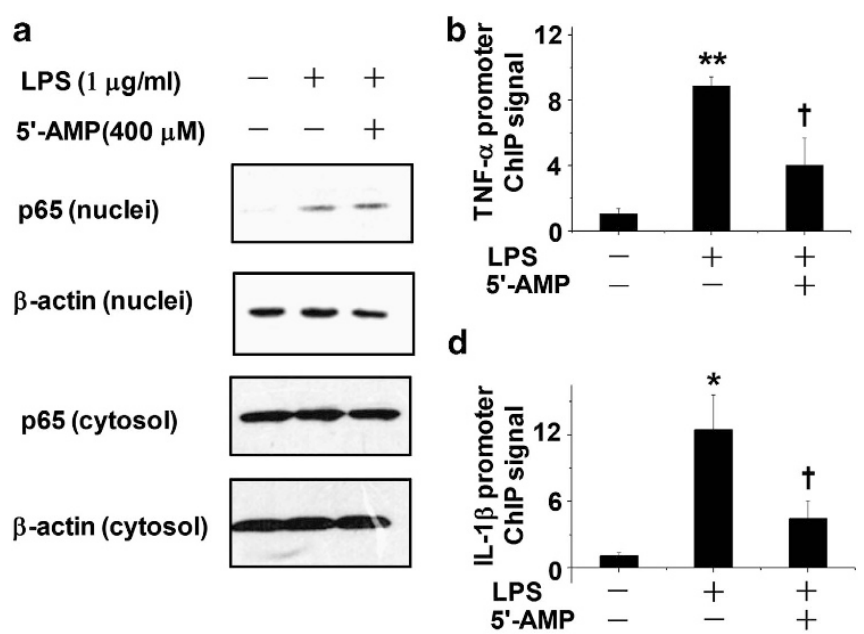

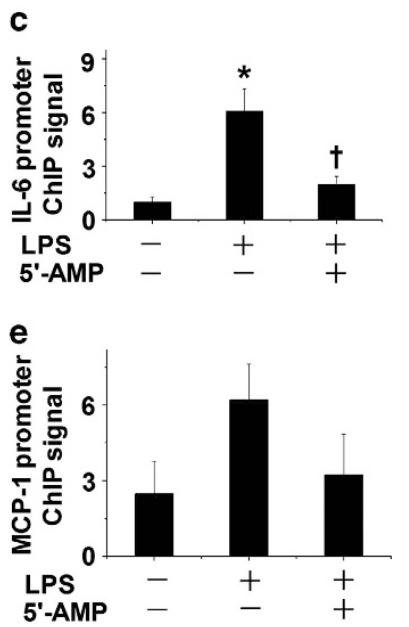

Figure $5 \quad 5^{\prime}$-AMP attenuates LPS-induced NF- $\kappa$ B activation in RAW264.7 cells. RAW264.7 cells were pretreated with $5^{\prime}$-AMP $(400 \mu \mathrm{M})$ for 30 min and then stimulated with LPS $(1 \mu \mathrm{g} / \mathrm{ml})$ for $1 \mathrm{~h}$. (a) Nuclear and cytosolic extracts were prepared for the western blot analysis of NF- $\kappa$ B protein using specific anti-p65 antibody, and $\beta$-actin were used as internal control. Cross-link chromatin was analyzed for recruitment of NF- $\kappa$ B p65 to TNF- $\alpha$ (b), IL-6 (c), IL-1 $\beta$ (d), and MCP-1 (e) promoters by ChIP assay. Data are expressed as mean \pm S.E. of four independent experiments. ${ }^{*} P<0.05,{ }^{* \star} P<0.01$ versus vehicle/vehicle group; ${ }^{\dagger} P<0.05$ versus vehicle/LPS group
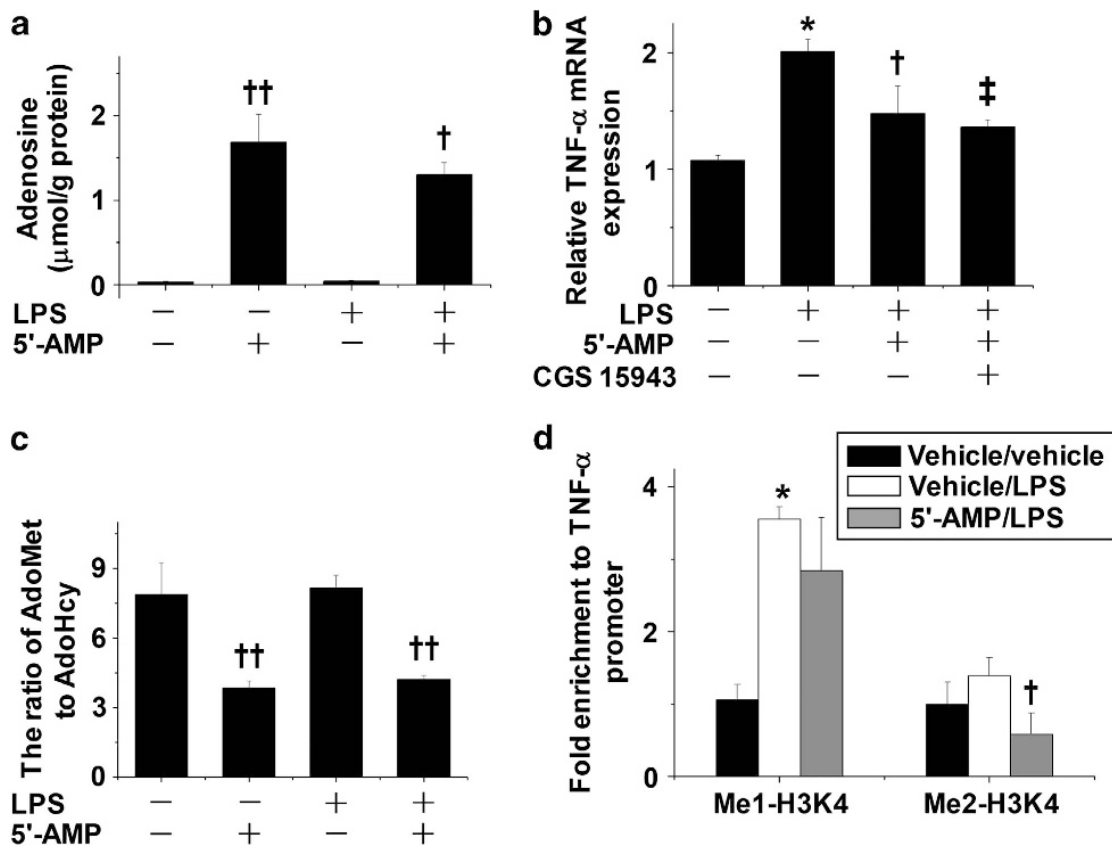

Figure $6 \quad 5^{\prime}$-AMP decreases LPS-induced the enrichment of H3K4 methylation at the TNF- $\alpha$ promoter. RAW264.7 cells were pretreated with $5^{\prime}$-AMP (400 $\mu$ M) for 30 min and then stimulated with LPS $(1 \mu \mathrm{g} / \mathrm{ml})$ for $1 \mathrm{~h}$. (a) Intracellular adenosine was determined by HPLC. (b) CGS15943 (50 $\mu \mathrm{M})$ was stimulated 30 min before $5^{\prime}$-AMP. The mRNA expressions of TNF- $\alpha$ was measured by quantitative RT-PCR at $6 \mathrm{~h}$ after LPS stimulation. (c) The ratio of AdoMet to AdoHcy was determined by HPLC. (d) ChIP assay was used to assess the binding of two methylated forms of H3K4 (Me1-H3K4 and Me2-H3K4) to the $\kappa$ B-binding region on the TNF- $\alpha$ promoter. Data are expressed as mean \pm S.E. of four independent experiments. ${ }^{\star} P<0.05$ versus vehicle/vehicle group; ${ }^{\dagger} P<0.05,{ }^{\dagger} P<0.01$ versus vehicle/LPS group; ${ }^{\ddagger} P<0.05$ versus $5^{\prime}$-AMP/LPS group

revealed that treatment of $5^{\prime}$-AMP decreased the ratio of AdoMet to AdoHcy compared with control group (Figure 6c). Subsequently, we performed chromatin immunoprecipitation (ChIP) analysis to detect the levels of methylated H3K4 to the TNF- $\alpha$ promoter containing two key $\kappa \mathrm{B}$ sites. LPS treatment induced the binding of monomethylated and dimethylated H3K4 to the TNF- $\alpha$ promoter. Pretreatment with $5^{\prime}$-AMP lowered the binding of monomethylated H3K4 and prevented the LPS-induced binding of dimethylated H3K4 (Figure 6d).
Adenosine directly attenuates LPS-induced recruitment of NF- $\boldsymbol{\kappa}$ B to the TNF- $\alpha$ and IL- 6 promoters. To clarify whether 5'-AMP-induced hyperadenosine could directly contribute to a decrease in inflammatory gene expression, an in vitro biochemical analysis was performed to determine the function of adenosine on recruitment of $N F-\kappa B$ to the TNF- $\alpha$ and IL- 6 promoters. The ChIP assays revealed that adenosine directly attenuated LPS-induced recruitment of NF- $\kappa$ B to TNF- $\alpha$ and IL- 6 promoters (Figures $7 a$ and $b$ ), and it 

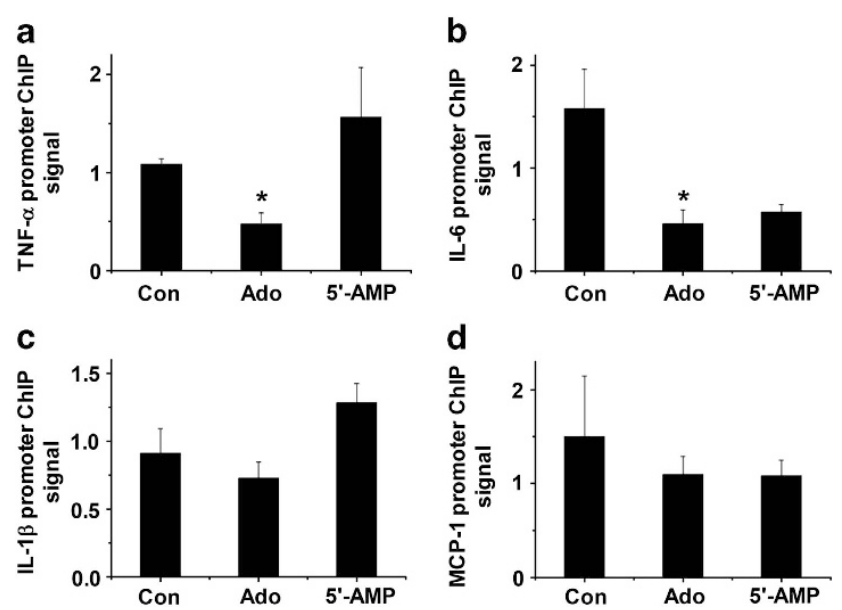

Figure 7 Treatment of adenosine directly decreases the recruitment of NF- $\kappa$ B to the TNF- $\alpha$ and IL-6 promoters. RAW264.7 cells were stimulated with LPS $(1 \mu \mathrm{g} / \mathrm{ml})$ for $1 \mathrm{~h}$. Cross-linked chromatin were sonicated into DNA fragments. The same sonicated cell lysates were incubated with adenosine $(400 \mu \mathrm{M})$ or $5^{\prime}$-AMP $(400 \mu \mathrm{M})$ at $37^{\circ} \mathrm{C}$ for $30 \mathrm{~min}$. ChIP assay was used to assess the binding of NF- $\kappa \mathrm{B}$ to TNF- $\alpha$ (a), IL-6 (b), IL-1 $\beta$ (c), and MCP-1 (d) promoters. Data are expressed as mean \pm S.E. of four independent experiments. ${ }^{\star} P<0.05$ versus control group

had no significant effect on the IL-1 $\beta$ and MCP- 1 promoters (Figures 7c and d). However, incubation with 5'-AMP failed to decrease the recruitment of $\mathrm{NF}-\kappa \mathrm{B}$ to these inflammatory gene promoters directly (Figures $7 a-d)$.

\section{Discussion}

The significance of endotoxin (i.e., LPS)-mediated macrophage activation and inflammatory responses in acute and chronic liver diseases is well known. ${ }^{30}$ GalN/LPS-induced ALF in mice has been used as a promising animal model for elucidating the efficiency of hepatoprotectives. ${ }^{24}$ Adenosine is released in the vicinity of immune cells in tissues subjected to various forms of injurious stimuli, including ischemia and inflammation. On the basis of the evidence summarized, adenosine appears to promote a self-limiting, healthy immune response. $^{31}$ Several observations reveal that adenosine receptors have a regulatory function in inflammatory responses in vitro. ${ }^{22,23}$ In the current study, we found that in mice model of GalN/LPS-induced ALF, hepatic adenosine feedback increased, and GalN/LPS induced similar lethality in WT and adenosine receptor-deficient mice, indicating that adenosine receptors did not have an essential role in the development of GalN/LPS-induced ALF in mice. Our results here, for the first time, demonstrated that the elevated cellular adenosine induced by $5^{\prime}$-AMP pretreatment confers protection against GalN/LPS-induced ALF. Treatment with 5'-AMP before GalN/LPS markedly decreased the lethality, reduced the elevation of serum AST and ALT activities, mitigated hepatic necrosis, attenuated inflammatory cell infiltration, and lowered the number of infiltrating monocytes/macrophages.

It has been reported that survival and apoptotic liver injury in response to GalN/LPS are mainly dependent on secreted TNF- $\alpha$ signaling. ${ }^{32}$ A variety of agents have been reported to prevent lethal liver injury by regulating the activity of TNF- $\alpha$ in GalN/LPS-treated mice. Among these agents, melatonin, ${ }^{33}$ epotoside, ${ }^{34}$ acteoside, ${ }^{35}$ palmatine, ${ }^{36}$ and melittin ${ }^{24}$ attenuated mortality and liver injury in ALF by inhibiting the inflammatory response and apoptosis. In the present study, we observed that proinflammatory cytokines such as TNF- $\alpha$ and IL-6 significantly inhibited mRNA expressions in the livers pretreated with $5^{\prime}$-AMP. Concomitant reduction of serum TNF- $\alpha$ and IL- 6 paralleled the liver cytokine profile, which was supported by in vitro experiments.

Several evidences demonstrated that GalN/LPS administration induces the activation of NF- $\kappa \mathrm{B} .{ }^{37}$ In the present study, 5 -AMP could not inhibit LPS-induced nuclear translocation of $\mathrm{NF}-\kappa \mathrm{B}$ p65, but suppressed transactivation activity of $\mathrm{NF}-\kappa \mathrm{B}$. It is known that histone methylation could modulate NF- $\kappa \mathrm{B}$ downstream genes. SET7/9, a chromatin histone H3-lysine 4 methyltransferase, is a key contributor to $\mathrm{NF}-\kappa \mathrm{B}$ transactivity and can regulate the expression of $\mathrm{NF}-\kappa \mathrm{B}$ downstream inflammatory genes by modulating $\mathrm{H} 3 \mathrm{~K} 4$ methylation at their promoters. $^{12}$ In our observations, 5'-AMP treatment decreased $\mathrm{H} 3 \mathrm{~K} 4$ methylation and reduced the recruitment of $\mathrm{NF}-\kappa \mathrm{B}$ p 65 to a subset of gene promoters in vitro. The change of histone methylation affects the efficiency of gene expression at several levels, including methylation of the promoters, cap formation, the stability and export of mRNA, and the initiation of translocation. ${ }^{38}$ The ratio of AdoMet to AdoHcy levels is used frequently as an indicator of cellular methylation capacity, whereby a decrease in this ratio predicts reduced cellular methylation potential. ${ }^{29}$ Adenosine inhibited AdoHcy hydrolysis in vitro and in vivo. Inhibition of AdoHcyase results in the intracellular accumulation of AdoHcy and thus potent inhibition of some AdoMet-dependent methyltransferases. ${ }^{38}$ Although 5'-AMP treatment elevated cellular adenosine level, the ratio of AdoMet to AdoHcy was decreased and LPSinduced enrichment of $\mathrm{H} 3 \mathrm{~K} 4$ dimethylation at the TNF- $\alpha$ promoter was attenuated, resulting in the reduction of downstream inflammation gene expression.

More recent evidence indicated that adenosine helps to maintain tissue integrity by modulating of immune system function. It appears that the release of adenosine followed by its binding to adenosine receptors on immune cells represent a potent endogenous immunosuppressive pathway that regulates the exuberant immune response to harmful external insults. ${ }^{31,39}$ Pharmacologically enhanced release of endogenous adenosine could be utilized to diminish inflammation. ${ }^{40}$ There is evidence that some therapeutic agents, such as sulfasalazine and FK-506, could exert their anti-inflammatory effects by promoting adenosine release. ${ }^{41,42}$ It is possible that adenosine receptors have a role in physiological state. However, pathological elevation of intracellular adenosine could directly regulate cellular biochemical process.

In fact, many investigations indicate that adenosine had several direct biochemical functions. The aptazyme is based on the 8-17 DNAzyme with an adenosine aptamer motif that can modulate the DNAzyme activity through allosteric interactions depending on the presence of adenosine. ${ }^{43}$ Adenosine also directly stimulated G-6-Pase enzyme activity in a dose-dependent manner. ${ }^{19}$ Our current results show that elevated adenosine can directly attenuate LPS-induced recruitment of NF- $\kappa$ B to TNF- $\alpha$ and IL- 6 promoters in a nocell system. Moreover, elevated adenosine resulted in a decreasing tendency of recruitment of NF- $\kappa \mathrm{B}$ to $\mathrm{IL}-1 \beta$ and 
MCP-1 promoter. Small molecules such as sesquiterpene lactones have been reported to inhibit NF- $\kappa$ B by interacting with cysteine 38 in the DNA-binding loop of RelA. ${ }^{44}$ The effects of adenosine on the recruitment of NF- $\kappa$ B to different inflammation gene promoters could vary with their different binding affinities. Our findings suggest a novel inhibitory mechanism on regulation of inflammation gene expression by 5'-AMP-induced hyperadenosine, whereas administration of adenosine fails to cause high level of cellular adenosine due to its small solubility in saline.

In summary, the elevated cellular adenosine induced by 5'-AMP pretreatment directly attenuated LPS-induced recruitment of NF- $\kappa$ B and indirectly decreased LPS-induced enrichment of H3K4 dimethylation at the TNF- $\alpha$ promoter through decreasing ratio of AdoMet to AdoHcy (Figure 8), reducing the downstream inflammation gene expression. This inhibition of $5^{\prime}$-AMP on inflammatory response was not mediated by adenosine receptors, suggesting 5'-AMP may represent a potential protective agent for amelioration of LPS-induced liver failure.

\section{Materials and Methods}

Animals. Male WT C57BL/6J mice and $A_{1} A R^{-1-}, A_{2 a} A R^{-1-}, A_{2 b} A R^{-1-}$ and $A_{3} A R^{-1-}$ (C57BL/6 background) mice were used at 8-10 weeks of age with a body weight of $20-25 \mathrm{~g}$ in this work. Mice were maintained under standard laboratory conditions, with full access to food and water ad libitum, and $12 \mathrm{~h} \mathrm{light/}$ $12 \mathrm{~h}$ dark cycles with lights on at $0700 \mathrm{~h}$ and off at $1900 \mathrm{~h}$. All experiments were in accordance with the guidelines of the Animal Care and Use Committee at Nanjing University of Science and Technology.

ALF model. For induction of ALF, GaIN (Sigma-Aldrich, St Louis, MO, USA) and E. coli LPS (serotype O55:B5, Sigma-Aldrich) were together dissolved in PBS and was injected intraperitoneally (i.p.) into WT mice and $A_{1} A R^{-1-}, A_{2 a} A R^{-1-}$, $A_{2 b} A R^{-1-}$ and $A_{3} A R^{-1-}$ mice at a dose of GalN $(500 \mathrm{mg} / \mathrm{kg}$ body weight) and E. coli LPS $(5 \mu \mathrm{g} / \mathrm{kg}$ body weight). PBS was used as vehicle control for all experiments. For $5^{\prime}$-AMP-pretreated survival experiment, WT mice were randomly divided into two groups ( $n=15$ in each group). $5^{\prime}$-AMP ( $5 \mathrm{mg} / 20 \mathrm{~g}$ body weight i.p.)
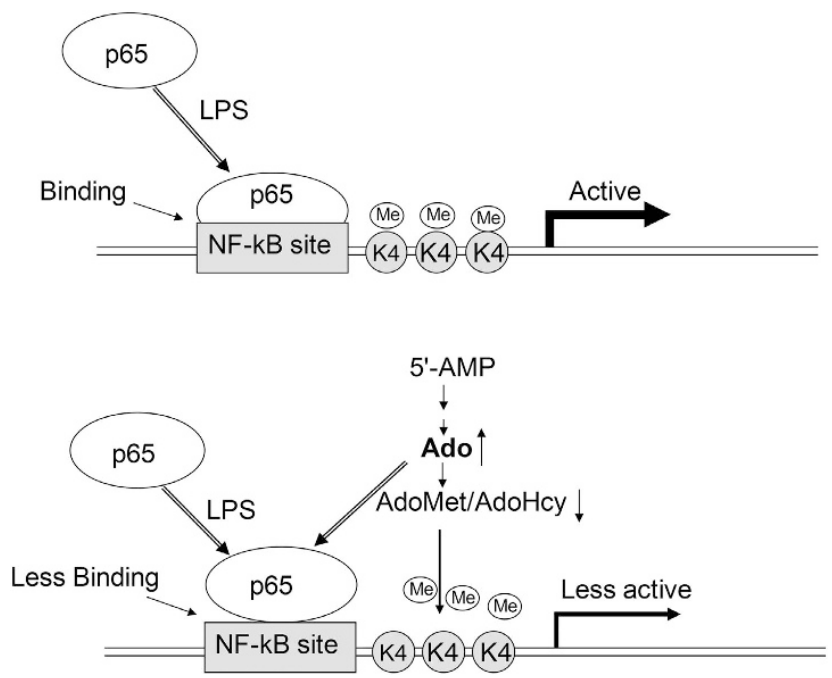

Figure 8 Schematic representation of proposed regulatory function of 5'-AMP on NF- $\kappa$ B modulating inflammatory gene expression. $5^{\prime}$-AMP can elevate intracellular adenosine level, which directly attenuated LPS-induced recruitment of NF- $\kappa \mathrm{B}$ and indirectly decreased LPS-induced enrichment of H3K4 dimethylation at a subset of gene promoters, resulting in the reduction of downstream inflammation gene expression and the prevention of ALF or PBS was administered to mice at 30 min before GalN/LPS administration. We observed the survival of $5^{\prime}$-AMP-treated mice and PBS-treated mice for 5 days. For general experiment, WT mice were randomly divided into four groups $(n=5$ in each group): (1) vehicle/vehicle group; (2) 5'-AMP/vehicle group; (3) vehicle/GalN-LPS group; (4) 5'-AMP/GalN-LPS group. Mice were killed at $4 \mathrm{~h}$ after administration of GalN/LPS. The blood was collected from the carotid artery and the liver of each mouse was removed immediately and then was kept at $-80^{\circ} \mathrm{C}$ until analyzed.

Serum biochemistry and cytokine assay. Activities of serum AST and ALT were measured using an AU2700 automatic biochemical analyzer (Olympus, Tokyo, Japan). TNF- $\alpha$ and IL-6 levels in serum were determined by enzyme-linked immunosorbent assay (ELISA) kits (Boster Biological Technology Ltd., Wuhan, China) according to the manufacturer's protocol.

Histological analysis. Liver tissue was fixed in 10\% neutral buffered formalin and paraffin embedded, and cut into $4 \mu \mathrm{m}$ sections. Sections were stained with $\mathrm{H} \& \mathrm{E}$. For immunohistochemical analysis, paraffin-embedded sections were used for immunostaining for cell surface marker, CD68 (expressed particularly on monocytes/macrophages), as described previously ${ }^{45,46}$ with slight modification. Sections were deparaffinized and rehydrated, followed by incubation in $3 \% \mathrm{H}_{2} \mathrm{O}_{2}$ for 10 min. After blocking with $5 \% \mathrm{BSA}$, the sections were incubated with anti-CD68 (1:100, Millipore, Bedford, MA, USA) overnight at $4{ }^{\circ} \mathrm{C}$, followed by biotinylated secondary antibodies $(1: 200$, Santa Cruz Biotechnology, Santa Cruz, CA, USA) for 30 min and incubation with HRP-streptavidin (1:400, Invitrogen, Carlsbad, CA, USA) for $30 \mathrm{~min}$. Color development was performed with DAB for 3-5 min.

Cell culture and cell treatment. The RAW264.7 cells (a murine macrophage cell line) were maintained in supplemented RPMI 1640 in an atmosphere at $90 \%$ humidity containing $5 \% \mathrm{CO}_{2}$ at $37^{\circ} \mathrm{C}$. At the end of the pre-incubated period, cells were rinsed with PBS and the medium was supplemented with RPMI 1640 without fetal bovine serum. The cells were pretreated with $5^{\prime}$-AMP $(400 \mu \mathrm{M})$ for $30 \mathrm{~min}$ and then stimulated with LPS $(1 \mu \mathrm{g} / \mathrm{ml})$ for indicated time. CGS15943 (50 $\mu \mathrm{M}$, Santa Cruz Biotechnology) was stimulated $30 \mathrm{~min}$ before $5^{\prime}$-AMP.

Cell cytokine assay. RAW264.7 cells were stimulated with LPS for $24 \mathrm{~h}$. TNF- $\alpha$ and IL- 6 levels in the supernatant were assessed using ELISA kits (Boster Biological Technology Ltd.) according to the manufacturer's protocol.

RNA isolation and quantitative RT-PCR. Total RNA was extracted from fresh liver samples or RAW264.7 cell samples with Trizol (Invitrogen) according to the manufacturer's instructions. Twenty nanograms of RNA was converted to cDNA using reverse transcript enzyme (Invitrogen). Quantitative RT-PCR was performed and results were analyzed using an ABI 7300 Detection System utilizing SYBR Green dye (Toyobo, Osaka, Japan). All primer sequences used for quantitative RT-PCRs are shown in Supplementary Table S1. Relative gene expression in comparison with Gapdh expression was calculated by the comparative cycle threshold method.

Western blot analysis. RAW264.7 cells were plated in 100-mm dishes and stimulated with LPS for $1 \mathrm{~h}$. The cytoplasmic and nuclear proteins were extracted following the procedure described previously. ${ }^{47,48}$ Preparation of total protein extracts from mice liver was performed. The extracted proteins were separated by SDS-PAGE $12 \%$ polyacrylamide gel and then electrically transferred to a PVDF membrane. After blocking with $5 \%$ (w/v) BSA in TBST at room temperature for $1 \mathrm{~h}$, the membranes were then incubated with an appropriate specific primary antibody (anti-NF- $\kappa$ B p65, 1:500; anti- $\beta$-actin, 1: 1000; Bioworld, Minnesota, MN, USA. anti-CD14, 1:500; anti-TLR4, 1:500; Santa Cruz Biotechnology) at $4{ }^{\circ} \mathrm{C}$ overnight, followed by incubation with HRP-conjugated secondary antibody (1:10000; Sunshine Biotechnology, Nanjing, China) and detected by enhanced chemical luminescence kit (Thermo Scientific, Hudson, NH, USA).

ChIP assays. ChIP assay was performed as described previously ${ }^{49,50}$ with slight modification. RAW264.7 cells were plated in $100-\mathrm{mm}$ dishes and stimulated with LPS for $1 \mathrm{~h}$. Cross-linked chromatin were sonicated into DNA fragment of $0.5-1.0 \mathrm{~kb}$. Sonicated cell lysates were diluted and precleared with $50 \%$ salmon sperm DNA-saturated protein A agarose beads. Chromatin was immunoprecipitated with $5 \mu \mathrm{g}$ of antibody (anti-NF- $\kappa \mathrm{B}$ p65, Bioworld; anti-Me1-H3K4, anti-Me2$\mathrm{H} 3 \mathrm{~K} 4$, Millipore), or negative control rabbit $\operatorname{lgG}$ (Millipore) at $4{ }^{\circ} \mathrm{C}$ overnight. 
Immunoprecipitated DNA was then used as template for quantitative RT-PCR as described above. The promoter primer pairs spanning contains NF- $\kappa$ B-binding region. All primer sequences used for ChIP-quantitative PCRs are listed in Supplementary Table S1. For in vitro biochemical experiments, the same sonicated cell lysates were incubated with adenosine $(400 \mu \mathrm{M})$ or $5^{\prime}$-AMP $(400 \mu \mathrm{M})$ at $37^{\circ} \mathrm{C}$ for $30 \mathrm{~min}$. Then chromatin was precleared with $50 \%$ salmon sperm DNA-saturated protein A agarose beads and immunoprecipitated with $5 \mu \mathrm{g}$ of antibody (anti-NF- $\kappa$ B p65, Bioworld).

HPLC analysis of adenosine, AdoMet, and AdoHcy. Adenosine, AdoMet, and AdoHcy were extracted from liver samples and cells using $0.4 \mathrm{~N}$ perchloric acid and analyzed by HPLC, as described previously. ${ }^{51,52}$ Extracts were separated and quantified using reverse-phase HPLC (Waters 1525 system; Millipore) on a Partisphere bounded phase $\mathrm{C} 18$ (reverse phase) cartridge column. The mobile phase contained $0.1 \mathrm{M}$ sodium acetate, $5 \mathrm{mM}$ heptanesulfonic acid adjusted to $\mathrm{pH} 4.5$ with acetic acid, and $4.2 \%$ acetonitrile. Pure adenosine, AdoMet, and AdoHcy (Sigma-Aldrich) were used to identify the peaks and obtain the calibration curves.

Statistics. The statistical significance of lethality was analyzed using the Kaplan-Meier method. Other results were presented as the mean \pm S.E. Comparison of multiple groups was performed using one-way ANOVA followed by Tukey's post-hoc test. The differences were considered statistically significant at $P<0.05$.

\section{Conflict of Interest}

The authors declare no conflict of interest.

Acknowledgements. This work was supported by the grant from National Key Basic Research Program of China (number 2012CB517505, 2013CB945203) and National Nature Science Foundation of China (number 31071130).

1. Zanobbio L, Palazzo M, Gariboldi S, Dusio GF, Cardani D, Mauro V et al. Intestinal glucose uptake protects liver from lipopolysaccharide and D-galactosamine, acetaminophen, and alpha-amanitin in mice. Am J Pathol 2009; 175: 1066-1075.

2. Lee WM. Acute liver failure. Semin Respir Crit Care Med 2012; 33: 36-45.

3. Lee WM, Squires Jr RH, Nyberg SL, Doo E, Hoofnagle JH. Acute liver failure: summary of a workshop. Hepatology 2008; 47: 1401-1415.

4. Stuart WD, Kulkarni RM, Gray JK, Vasiliauskas J, Leonis MA, Waltz SE. Ron receptor regulates Kupffer cell-dependent cytokine production and hepatocyte survival following endotoxin exposure in mice. Hepatology 2011; 53: 1618-1628.

5. Wang $Y$, Singh R, Xiang $Y$, Greenbaum LE, Czaja MJ. Nuclear factor $\kappa B$ up-regulation of CCAA/enhancer-binding protein $\beta$ mediates hepatocyte resistance to tumor necrosis factor $\alpha$ toxicity. Hepatology 2010; 52: 2118-2126.

6. Pålsson-McDermott EM, O'Neill LA. Signal transduction by the lipopolysaccharide receptor, Toll-like receptor-4. Immunology 2004; 113: 153-162.

7. Dauphinee SM, Karsan A. Lipopolysaccharide signaling in endothelial cells. Lab Invest 2006; 86: 9-22.

8. Vallabhapurapu S, Karin M. Regulation and function of NF- $\mathrm{KB}$ transcription factors in the immune system. Annu Rev Immunol 2009; 27: 693-733.

9. Oeckinghaus A, Ghosh S. The NF-kappa B family of transcription factors and its regulation. Cold Spring Harb Perspect Biol 2009; 1: a000034.

10. Ogushi I, limuro Y, Seki E, Son G, Hirano T, Hada T et al. Nuclear factor kappa B decoy oligodeoxynucleotides prevent endotoxin-induced fatal liver failure in a murine model. Hepatology 2003; 38: 335-344.

11. Ambade A, Catalano D, Lim A, Mandrekar P. Inhibition of heat shock protein (molecular weight $90 \mathrm{kDa}$ ) attenuates proinflammatory cytokines and prevents lipopolysaccharideinduced liver injury in mice. Hepatology 2012; 55: 1585-1595.

12. Li Y, Reddy MA, Miao F, Shanmugam N, Yee JK, Hawkins D et al. Role of the histone H3 lysine 4 methyltransferase, SET7/9, in the regulation of NF-kappaB-dependent inflammatory genes. Relevance to diabetes and inflammation. J Biol Chem 2008; 283: 26771-26781.

13. Olleros ML, Vesin D, Fotio AL, Santiago-Raber ML, Tauzin S, Szymkowski DE et al. Soluble TNF, but not membrane TNF, is critical in LPS-induced hepatitis. Hepatology 2010; 53: 1059-1068.

14. Wang K, Damjanov I, Wan YJ. The protective role of pregnane $\mathrm{X}$ receptor in lipopolysaccharide/D-galactosamine-induced acute liver injury. Lab Invest 2010; 90: 257-265.

15. Zhang J, Kaasik K, Blackburn MR, Lee CC. Constant darkness is a circadian metabolic signal in mammals. Nature 2006; 439: 340-343.
16. Daniels IS, Zhang J, O'Brien WG 3rd, Tao Z, Miki T, Zhao Z et al. A role of erythrocytes in adenosine monophosphate initiation of hypometabolism in mammals. J Biol Chem 2010; 285: 20716-20723.

17. Wasserman HA, Singh S, Champagne DE. Saliva of the yellow fever mosquito, Aedes aegypti, modulates murine lymphocyte function. Parasite Immunol 2004; 26: 295-306.

18. Van den Berge M, Polosa R, Kerstjens HA, Postma DS. The role of endogenous and exogenous AMP in asthma and chronic obstructive pulmonary disease. J Allergy Clin Immunol 2004; 114: 737-746.

19. Zhang Y, Wang Z, Zhao Y, Zhao M, Wang S, Huang Z et al. The plasma $5^{\prime}$-AMP acts as a potential upstream regulator of hyperglycemia in type 2 diabetic mice. Am J Physiol Endocrinol Metab 2012; 302: 325-333.

20. Fujimoto Y, Nakatani N, Kubo T, Semi Y, Yoshida N, Nakajima H et al. Adenosine and ATP affect LPS-induced cytokine production in Canine macrophage cell line DH82 cells. $J$ Vet Med Sci 2012; 74: 27-34.

21. Livingston M, Heaney LG, Ennis M. Adenosine, inflammation and asthma-a review. Inflamm Res 2004; 53: 171-178.

22. Frick JS, MacManus CF, Scully M, Glover LE, Eltzschig HK, Colgan SP. Contribution of adenosine $\mathrm{A} 2 \mathrm{~b}$ receptors to inflammatory parameters of experimental colitis. $\mathrm{J}$ Immunol 2009; 182: 4957-4964

23. Schnurr M, Toy T, Shin A, Hartmann G, Rothenfusser S, Soellner J et al. Role of adenosine receptors in regulating chemotaxis and cytokine production of plasmacytoid dendritic cells. Blood 2004; 103: 1391-1397.

24. Park JH, Kim KH, Lee WR, Han SM, Park KK. Protective effect of melittin on inflammation and apoptosis in acute liver failure. Apoptosis 2012; 17: 61-69.

25. Kim JK, Jun JG. Ailanthoidol suppresses lipopolysaccharide-stimulated inflammatory reactions in RAW264.7 cells and endotoxin shock in mice. J Cell Biochem 2011; 112: 3816-3823.

26. Tak PP, Fiestein GS. NF-kB: a key role in inflammatory diseases. J Clin Invest 2001; 107: 7-11.

27. Rego D, Kumar A, Nilchi L, Wright K, Huang S, Kozlowski M. IL-6 production is positively regulated by two distinct Src homology domain 2-containing tyrosine phosphatase-1 (SHP-1)-dependent CCAAT/enhancer-binding protein $\beta$ and NF- $\mathrm{KB}$ pathways and an SHP-1-independent NF- $\kappa B$ pathway in lipopolysaccharide-stimulated bone marrowderived macrophages. J Immunol 2011; 186: 5443-5456.

28. Wang Y, Rangan GK, Goodwin B, Tay YC, Harris DC. Lipopolysaccharide-induced MCP-1 gene expression in rat tubular epithelial cells is nuclear factor-kappaB dependent. Kidney Int 2000; 57: 2011-2022.

29. Perna AF, Ingrosso D, Castaldo P, Galletti P, De Santo NG. Homocysteine and transmethylations in uremia. Kidney Int Suppl 2001; 78: S230-S233.

30. Nolan JP. The role of intestinal endotoxin in liver injury: a long and evolving history. Hepatology 2010; 52: 1829-1835.

31. Haskó G, Cronstein BN. Adenosine: an endogenous regulator of innate immunity. Trends Immunol 2004; 25: 33-39.

32. Mignon A, Rouquet N, Fabre M, Martin S, Pages JC, Dhainaut JF et al. LPS challenge in D-galactosamine-sensitized mice accounts for caspase-dependent fulminant hepatitis, not for septic shock. Am J Respir Crit Care Med 1999; 159: 1308-1315.

33. Wang H, Xu DX, Lv JW, Ning H, Wei W. Melatonin attenuates lipopolysaccharide -induced liver injury. Life Sci 2009; 65: 421-430.

34. Nakama T, Hirono S, Moriuchi A, Hasuike S, Nagata K, Hori T et al. Etoposide prevents apoptosis in mouse liver with D-galactosamine/lipopolysaccharide-induced fulminant hepatic failure resulting in reduction of lethality. Hepatology 2001; 33: 1441-1450.

35. Xiong $Q$, Hase K, Tezuka $Y$, Namba T, Kadota S. Acteoside inhibits apoptosis in D-galactosamine and lipopolysaccharide-induced liver injury. Life Sci 1999; 65: 421-430.

36. Lee WC, Kim JK, Kang JW, Oh WY, Jung JY, Kim YS et al. Palmatine attenuates D-galactosamine/lipopolysaccharide-induced fulminant hepatic failure in mice. Food Chem Toxicol 2009; 48: 222-228.

37. Ben-Ari Z, Zilbermints V, Pappo O, Avlas O, Sharon E, Greif F et al. Erythropoietin increases survival and attenuates fulminant hepatic failure injury induced by D-galactosamine/lipopolysaccharide in mice. Transplantations 2011; 92: 18-24.

38. Kloor D, Osswald H. S-Adenosylhomocysteine hydrolase as a target for intracellular adenosine action. Trends Pharmacol Sci 2004; 25: 294-297.

39. Cronstein BN. Adenosine, an endogenous anti-inflammatory agent. J Appl Physiol. 1994; 76: 5-13.

40. Cronstein BN, Eberle MA, Gruber HE, Levin RI. Methotrexate inhibits neutrophil function by stimulating adenosine release from connective tissue cells. Proc Natl Acad Sci USA 1991; 88: 2441-2445.

41. Gadangi $\mathrm{P}$, Longaker M, Naime D, Levin RI, Recht PA, Montesinos MC et al. The antiinflammatory mechanism of sulfasalazine is related to adenosine release at inflamed sites. $J$ Immunol 1996; 156: 1937-1941.

42. Hwang KK, Hall CS, Spielman WS, Sparks HV. FK506 promotes adenosine release from endothelial cells via inhibition of adenosine kinase. Eur J Pharmacol 2001; 425: 85-93.

43. Liu J, Lu Y. Adenosine-dependent assembly of aptazyme-functionalized gold nanoparticles and its application as a colorimetric biosensor. Anal Chem 2004; 15: 1627-1632.

44. García-Piñeres AJ, Castro V, Mora G, Schmidt TJ, Strunck E, Pahl HL et al. Cysteine 38 in p65/NF-kappaB plays a crucial role in DNA binding inhibition by sesquiterpene lactones. J Biol Chem 2001; 276: 39713-39720.

45. Patsenker E, Popov Y, Stickel F, Schneider V, Ledermann M, Sägesser H et al. Pharmacological inhibition of integrin alphavbeta3 aggravates experimental liver fibrosis and suppresses hepatic angiogenesis. Hepatology 2009; 50: 1501-1511. 
46. Yearley JH, Xia D, Pearson CB, Carville A, Shannon RP, Mansfield KG. Interleukin-18 predicts atherosclerosis progression in SIV-infected and uninfected rhesus monkeys (Macaca mulatta) on a high fat/high cholesterol diet. Lab Invest 2009; 89: 657-667.

47. Shin JS, Baek SR, Sohn SI, Cho YW, Lee KT. Anti-inflammatory effect of pelubiprofen, 2-[4-(oxocyclohexylidenemethyl)-phenyl] propionic acid, mediated by dual suppression of COX activity and LPS-induced inflammatory gene expression via NF- $\mathrm{KB}$ inactivation. $\mathrm{J} \mathrm{Cell}$ Biochem 2011; 112: 3594-3603.

48. Xu X, Pan C, Zhang L, Ashida H. Immunomodulatory beta-glucan from Lentinus edodes activates mitogen-activated protein kinases and nuclear factor- $\kappa B$ in murine RAW264.7 macrophages. J Biol Chem 2011; 286: 31194-31198.

49. Kim JW, Jang SM, Kim CH, An JH, Kang EJ, Choi KH. New molecular bridge between RelA/p65 and NF- $\kappa B$ target genes via histone acetyltransferase TIP60 cofactor. J Biol Chem 2012; 287: 7780-7791.

50. Cooper ZA, Ghosh A, Gupta A, Maity T, Benjamin IJ, Vogel SN et al. Febrile-range temperature modifies cytokine gene expression in LPS-stimulated macrophages by differentially modifying NF- $\mathrm{kB}$ recruitment to cytokine gene promoters. Am J Physiol Cell Physiol 2010; 298: C171-C181.

51. Pang W, Zhang $Y$, Wang S, Jia A, Dong W, Cai $C$ et al. The mPlrp2 and $m C l p s$ genes are involved in the hydrolysis of retinyl esters in the mouse liver. J Lipid Res 2011; 52: 934-941.

52. Yang $P$, Chen $P$, Wang $T$, Zhan $Y$, Zhou M, Xia L et al. Loss of $A(1)$ adenosine receptor attenuates alpha-naphthylisothiocyanate-induced cholestatic liver injury in mice. Toxicol Sci 2013; 131: 128-138.

cc) $($ ()

Cell Death and Disease is an open-access journal published by Nature Publishing Group. This work is licensed under a Creative Commons Attribution-NonCommercialShareAlike 3.0 Unported License. To view a copy of this license, visit http://creativecommons.org/licenses/by-nc-sa/3.0/

Supplementary Information accompanies this paper on Cell Death and Disease website (http://www.nature.com/cddis) 